\title{
Human Papillomavirus Infection and Human Cancer
}

\author{
Elias Rubinstein and Marketta Järveläinen
}

Turku, Finland

\begin{abstract}
The article is a review and the aim is to discuss human papillomavirus (HPV)-associated human cancers. In the text, the concept of Harald zur Hausen plays an essential role.

Cervical, vulval, vaginal, penile, anal, orophrayngeal and conjunctival cancers are important neoplasias induced by HPVs. HPVs count annually worldwide for about $28 \%$ of the cancer incidence attributable to infections. HPV self-testing is an essential new method of HPV detection - it is gaining increasing importance. Another vital move is HPV vaccination.
\end{abstract}

Keywords: Human papillomavirus (HPV), viral infection, human cancer.

\section{Introduction}

\section{Aspects of Viral Infections}

\section{Unsuccesful Infections}

A viral infection is characterised to be abortive when a virus infects a cell or a host but is unable to finish the full cycle of its replication [Cann 2005].

\section{Acute Infections}

A lot of viral infections are acute and they are totally eliminated by our immune defence. Much of the virus replication occurs in typical acute infections before the start of fever or any other symp- toms this is the result of the virus replication as well as of the activation of the immune system [Cann 2005].

\section{Chronic Infections}

When an acute infection is prolonged, it is characterised to be chronic - in this case, the virus per- sists in the host for a significant period of time [Cann 2005].

\section{Persistent Infections}

In persistent infections, the virus may be present as well as replicate in the host for its whole life-span [Cann 2005]. The importance of persistent high-risk human papillomavirus (HPV) infection in anogenital as well as in non-anogenital cancer is discussed by zur Hausen [2011].

\section{Latent Infections}

In a latent infection, the involved virus can downregulate the expression of its gene as well as set up an inactive condition - the typical pattern is that this type of infections persists for the whole life of the host [Cann 2005].

\section{The Aim of the Paper}

The aim of this review is to discuss HPVassociated human cancers. In this text, the concept of Harald zur Hausen [2011] plays an essential role.

Copyright (C) 2012 Elias Rubinstein and Marketta Järveläinen. This is an open access article distributed under the Creative Commons Attribution License unported 3.0, which permits unrestricted use, distribution, and reproduction in any medium, provided that original work is properly cited. Contact author: Elias Rubinstein E-mail: elias.rubinstein@pp.inet.fi 


\section{Epidemiology \& Transmission}

\section{Definitions}

\section{Prevalence \& Incidence}

Prevalence is made up of clinical or subclinical cases recorded at a specific time - all the cases are expressed as a proportion of the population which is studied. Incidence, on the other hand, consists of cases recorded during a specific period, e.g. one calendar year. It is not seldom given as a number of cases, e.g./1,000 [Collier et al. 2011].

In the year 1996, HPV infections were found to be the most common sexually transmitted viral diseases in the UK [Collier et al. 2011].

\section{Why Epidemiology?}

Epidemiology predicts trends of diseases and is helpful in planning various health programmes and in evaluating their achievements. Epidemiology also gives us important information about e.g. dis- eases induced by various infections [Collier et al. 2011].

\section{On Sexually Transmitted Diseases (STDs)}

\section{Mainly Localised Viral Infections}

Diseases induced by infection caused by HPVs, herpes simplex viruses 1 \& 2 (HSV 1 \& HSV 2), adenoviruses as well as poxvirus are predominantly localised [Collier et al. 2011].

\section{Epidemiological Aspects of HPVs and Cervical Cancer}

The worldwide age-standardised rates of cervical cancer are given by Ferlay et al. [2004]. The rates of this neoplasia are discussed in detail by zur Hausen [2011] they are high e.g. in Africa, India as well as in South America.

\section{Viral Infections and Cancer}

\section{The Start}

According to zur Hausen [2006], Dennis Burkitt noted that a certain paediatric lymphoma occurred only in specific areas in Africa. Pulvertaft in Western Nigeria and Epstein \& Barr in Bristol started to develop methods in order to culture tissues for lymphomas as well as to establish lymphoblastoid cell lines. Epstein and his colleagues found a new virus, the EpsteinBarr virus (EBV), belonging to the family of herpesviruses.

It is interesting to note that scientists did not understand the significance of the very first findings in this important field - the infectious aetiology of human cancers was an unconventional thought [zur Hausen 2006].

\section{The Concept Wins Support}

The unconventional thought of infections causing human cancer started, however, to change - the association between hepatitis $B$ virus and cancer of the liver as well as between a retrovirus and an unusual form of human leukaemia was understood. Finally, the essential role of HPVs in diseases of the skin and of the uterine cervix, the anogenital tract, as well as in neoplasias of the oropharynx was characterised [zur Hausen 2006].

\section{HPV Proteins and Their Functions}

In his two books, zur Hausen [2006, 2011] discusses in detail HPV proteins - mainly proteins of the high-risk HPV types - and their important functions. This discussion is highly essential to know why HPV infections are considered to be a major cause of human cancer.

Very recently, the genomic organisation and proteins of HPV as well as the oncogenic potential of different HPV types are discussed in a review article [Alp Avci 2012]. 


\section{Global Burden}

According to de Martel et al. [2012], 12.7 million new cases of cancer were diagnosed in the year $2008-16.1 \%$ of them were caused by infections. The percentages were $22.9 \%$ and $7.4 \%$ in devel- oping and developed countries respectively - the HPVs, hepatitis B \& C viruses and Helicobacter pylori counted for 1.9 million cases. Gastric and liver cancer as well as cancer of the uterine cervix were the most common neoplasias. In women, cancer of the uterine cervix counted for about half of the burden attributable to infections - about $30 \%$ of these cases occurred in patients younger than 50 .

In his comment on the article of de Martel et al. [2012], Goodarz Danaei [2012] states that, in spite of some limitations caused by available information, the authors have given the most relevant judgements concerning the role of infections in the development of cancer. The method used by the authors might, however, have resulted in an overestimate of the prevalence of cancer cases induced by infections in those conditions where other factors are involved, e.g. alcohol in cases of liver can- cer.

\section{HPV-Associated Cancers in the USA 2004-2008}

\section{Report from the Centers for Disease Control and Prevention (CDC)}

The CDC report [2012] includes cervical, vulval and vaginal as well as penile, anal (both sexes), and oropharyngeal (both sexes), but not a number of other cancers (e.g. carcinoma of the prostate). In an earlier paper, Dodd et al. [1993] state that the human prostate gland may perform a function as a reservoir of HPV.

\section{What Does this Report Add?}

In the USA, the CDC estimates that about 26,000 of annual cancer cases are probably caused by HPVs (about 8,000 in males and about 18,000 in females); about 12,000 of neoplasias in women are cervical cancers -
96\% of them attributable to HPVs [CDC 2012].

The numbers of annual cancers during the years 2004-2008 listed by the CDC report were as fol- lows: approximately 3,100 cases of vulval cancer $(51 \%$ HPVattributable), about 700 vaginal (64\% attributable to HPV), about 1,000 penile (36\% HPV-attributable), about 1,600 anal cancers in men as well as about 3,000 in women (93\% attributable to HPV). During those years, about 2,300 cases of oropharyngeal cancer were detected in women and about 9,300 cases in men $63 \%$ of the cases being probaly caused by HPVs [CDC 2012].

\section{HPV-Associated Cancers Worldwide}

\section{Cervical Cancer is the Number One}

CDC estimates, as is stated above, that $96 \%$ of the cervical cancers are probably caused by HPVs [CDC 2012]. The global incidence of this neoplasia is estimated to be 530,000 and the mortality 275,000 for the year 2008. The corresponding figures are 453,000 and 242,000 in developing compared to 76,000 and 32,000 in developed areas [Ferlay et al. 2012].

The estimated global incidence of cervical cancer has increased from 378,000 $(256,000-489,000)$ annual cases in the year 1980 to $454,000(318,000-620,000)$ - the annual rate of increase is esti- mated to be $0.6 \%$ [Forounzanfar et al. 2011].

The article of Forounzanfar et al. [2011] has been recently discussed by Ferlay et al. [2012]. This discussion underlines the importance of using statistical methods which ensures comparability.

\section{On Harald Zur Hausen'S HPV Concept}

\section{Cancer of the Cervix}

Zur Hausen [2011] underlines the difference between the global HPV percentage among women and men. The worldwide HPV percentage is $51.5 \%$ in women and $4.3 \%$ in men. He gives in his 
book the global age-standardised rates $/ 100,000$ of cervical cancer.

Cervical cancer is probably the best documented virus-induced human neoplasia. For the time be- ing, a great number of epidemiological studies confirm that high-risk HPVs do directly contribute to the development of cervical cancer. In this event, HPVs 16, 18, 31, 33, 35, 39, 45, $51,52,56,58,59$ and 66 are found to be involved - possibly also the HPV types 26 , 68,73 and 82 . The percentage of HPVpositive cases of cervical cancer is more than $95 \%$. HPV 16 is the most common HPV type found in cervical cancer (the relative percentage is 53.5), and is followed by HPV 18 (17.2), 45 (6.7), 31 (2.9), 33 (2.6), 52 (2.3) and 58 (2.2) [zur Hausen 2011].

\section{Cancer of the Penis}

HPV 16 and 18 are involved in basaloid and warty penile cancers, HPV 16 in keratinising carcin- omas. In the basaloid and warty carcinomas, the percentage of HPV-positive cases is $>50 \%$ but less than $10 \%$ in the keratinising type. It is interesting to note that several penile carcinomas are found to be only HPV 6 \& 11 DNA-positive [zur Hausen 2011].

\section{Vulval \& Vaginal Cancer}

The vulval carcinomas are also basaloid, warty or keratinising. The involved HPV types are the same as in penile cancers and the percentage of the HPV-positive tumours is the same. The basaloid and warty types are found in younger women and are usually HPV-positive [zur Hausen 2011].

The prognosis of vaginal cancers is worse than that of cervical cancers and the involved HPVs are HPV 16 \& 18 - over 50\% are HPV-positive [zur Hausen 2011].

\section{Anal Cancer}

Over $70 \%$ of anal cancers are HPV-positive and the HPV types involved are HPV 16 \& 18. The in-cidence of these tumours (of cancers as well as of precursor lesions) is high in homosexual men and notable in human immunodeficiency virus (HIV)positive individuals. Anal and perianal cancers are consistently linked to high-risk HPVs [zur Hausen 2011].

\section{Cancer of the Prostate Gland}

As stated above, Dodd et al. [1993] underlines that the human prostate gland may act as a reservoir of HPV. In his book, Zur Hausen [2011] declares that the role of HPVs is unclear in the develop- ment of the prostate cancer. Prostate cancer and STDs are positively connected to HPVs but it is unlikely that this neoplasia is induced by HPV.

\section{Cancer of Head and Neck \& Conjunctival Cancer}

Zur Hausen [2011] discusses in detail cancers of head and neck (including oral and cancer) as well as conjunctival cancer. Additional research is given below.

\section{Cancer of Head and Neck}

\section{Epidemiology}

In Finland, oropharyngeal cancer has doubled during the years 2004-2008 compared to 1989-1993. One important reason has been oral sex which exposes individuals to HPV infections. Since the year 2000, the number of HPV-positive cases in patients with oropharyngeal cancer has significant- ly increased - from $22 \%$ in $1990-1999$ to $41 \%$ in $2000-2007$ [Minn 2012].

In Sweden, a prospective survey showed that $75 \%$ of patients with oropharyngeal cancer were HPV-positive. Another Swedish study revealed that in the years $2000-2007,79 \%$ of patients with tonsillary carcinoma were HPV-positive - the corresponding figure was only $23 \%$ in 1970-1979. It is estimated that in 2012, 650-700 new cases of cancer of the head and neck will be diagnosed, and that at most $60-80 \%$ of these tumours will be HPV-positive [Minn 2012]. 
In a recent article, epidemiology of head and neck cancer is discussed. The authors conclude that excessive smoking and consumption of alcohol are essential risk factors but over $25 \%$ of head and neck cancers are now attributable to HPVs - the incidence is increasing [Joseph \& D'Souza 2012].

\section{Oral HPV Infections}

Rates and deciding factors of oral HPVinfection in a cohort of male university student were evalu- ated. Nearly $20 \%$ of sexually active participants exhibited oral HPV infection within twelve months. However, most of the infections were temporary. The prevalence of oral HPV 16 was found to be $2.8 \%$ [Edelstein et al. 2012].

\section{Oral \& Pharyngeal Cancer}

Zur Hausen [2011] underlines that HPVpositive oropharyngeal cancers are linked to practice of oral sex, multiple sexual partners as well as to condylomata acuminata.

Minn [2012] discusses the better prognosis of HPV-positive oropharyngeal cancer and states that the overall improvement of this cancer's prognosis is due to the increasing prevalence of HPV-posi-tive tumours.

Infections caused by HPVs are not uncommon in patients with squamous cell carcinomas of the oral cavity. In 173 advanced tumours, the prevalence of HPVs was $22 \%$. Patients with only HPV 16 infection were, however, at higher risk receiving distant metastases [Lee et al. 2012].

HPVs in the oral cavity are associated with oropharyngeal cancers but only HPV 16 is found to be clearly connected to these tumours [Paolini et al. 2012].

\section{Ocular Surface/Conjunctival Squamous Neoplasia (OSSN/CSN)}

\section{Conjunctival Intraepithelial Neoplasia (COIN)}

\section{General Considerations}

COIN is the most common intraepithelial tumour on the ocular surface. Its estimated incidence is $1.9 / 100,000$ persons per year. COIN is the precursor to the conjunctival squamous cell carcinoma (CSC); if it is not treated properly and without delay, the neoplasia invades the basement membrane of the epithelium as an invasive CSC (ICSC) necessitating radical surgery - it has the potential to send metastases. COIN (dysplasia) is found to be HPV16 \& 18associated [Scott et al. 2002].

The major risk factors of conjunctival neoplasias are ultraviolet light, drugs inducing immuno-suppression, HPV and HIV as well as an outdoor job, pale skin and/or iris, exposure to chemicals, medical treatment, a chronic inflammatory ocular disease, deficiency of vitamin A, a trauma linked with tools, contact lenses and, finally, actinic lesions of the skin [Aktas et al. 2012].

\section{HPV 16 \& 18 in COIN}

In a prospective study (case-controlled), ten consecutive patients with COIN went through an ex-cison. Five of the samples exhibited HPV 16 DNA \& RNA, the other five HPV 18 DNA \& RNA. None of the investigated controls was HPV-positive [Scott et al. 2002].

\section{Clinicopathological Correlations}

The clinicopathological patterns of OSSN are evaluated in a material of 612 consecutive cases. In this study, mild, moderate or severe dysplasia was found in $33 \%$ of the investigated cases $-52 \%$ were classified as conjunctival carcinoma in situ (CCIS) and 11\% as ICSCs [Kao et al. 2012].

\section{On HPV Prevalence in Ocular Lesio}

Di Girolamo [2012] reviewed 34 studies regarding the HPV prevalence in pterygium and OSSN. He found that it varied from 0 to $100 \%$. The prevalence was $18.6 \%$ (136 out of 731 cases) in the first lesion and 33.8 (144 out of 426 cases) in OSSN. Di Girolamo writes in a personal 
communication that the global incidence of OSSN is between 0.02 and 3.5/100,000.

In a material of 64 cases of OSSN, HPV infection was detected in $11 \%$ - it also indicated a better prognosis [Chauhan et al. 2012].

\section{On the Concept of Biswas}

\section{General Considerations}

According to the team of Biswas [2010], the conjunctival squamous lesions are squamous papil-loma and dysplasia as well as CCIS and ICSC. Squamous papillomas are often HPV-associated.

\section{Conjunctival Dysplasia}

Conjunctival dysplasia is a process where epithelium is replaced by squamous cells which are atyp-ical. The basal layers are first involved and the transition between normal and atypical epithelium is abrupt. In cases of low-grade (mild) dysplasia, less than $50 \%$ of the epithelial thickness shows atyp-ical squamous cells. In high-grade (severe) dysplasia, atypical cells are seen in over $50 \%$ of the epi-thelial thickness [Biswas et al. 2010].

\section{CCIS}

In CCIS, the entire epithelium exhibits malignant squamous cells but the basal membrane is undam-aged, and no invasion is seen [Biswas et al. 2010].

\section{ICSC}

ICSC shows invasion through the basal membrane - it is also able to invade other ocular structures [Biswas et al. 2010].

\section{Implications for Public Health}

\section{Persistent HPV Infections}

Persistent HPV infections cause virtually all cases of cervical cancer and a number of vulval, va-ginal, penile and anal cancers as well as a number of carcinomas in the oropharynx. It is highly important to know that these infections are sexually transmitted - sexual behaviour influences the incidence of these HPV-associated cancers as do the screening programmes and the recently intro- duced HPV vaccination [CDC 2012].

Future research will decide the true effect of HPV vaccination in preventing invasive cancers - we have to wait and see.

\section{Self-Testing}

Women are found to be positive to HPV self-testing [Rubinstein 2008]. Selfsampling is a new and highly essential method which is frequently discussed [Dunne et al. 2011; Gustavsson et al. 2011; Lazcano-Ponce et al. 2011; Jones et al. 2012; Mollers et al. 2012; Rositch et al. 2012; Snijders et al. 2012; Wolfrum et al. 2012].

The interesting aspect of HPV detection from urine samples is discussed in a review by Vorsters et al. [2011], and very recently by Tanzi et al. [2012] as well as by Thilagavathi et al. [2012].

\section{HPV Testing}

HPV testing can be performed by using the DNA or the RNA techniques. This method is discussed in several papers [zur Hausen 2006, 2011; Johansson et al. 2007; Twiggs \& Hopkins 2011; Chan et al. 2012; Guan et al. 2012].

\section{Hormonal Contraception Does Affect the Transmission of HPV}

Combined oral contraceptives (COCs) have been classified as a cause of cervical cancer (Agency for Research on Cancer, ARC). A collaborative reanalysis of data concerning 16,573 women with the disease and 35,509 women without it from 24 epidemiological studies worldwide showed that the relative risk of cervical cancer increased in women using COCs but decreased when women stopped to use them. When COCs are used in ten years from about the age of 20 to about the age of 30 , the cumulative incidence of invasive cervical cancer is calculated to increase by the age of 50 from 7.3 to $8.3 / 1,000$ in developing countries 
and from 3.8 to $4.5 / 1,000$ in developed areas [Appelby et al. 2007].

Zur Hausen [2011] discusses this important issue in his book referring to epidemiological as well as other studies. The results of these trials are published before the calendar year 2007 and indicate that long-term use of oral contraceptives (OCs) may stimulate gene activity in persisting HPV in- fections, and probably also prolong the duration of these infections.

It is essential to note that the use of OCs facilitates promiscuous sexual behaviour which highly affects the transmission of HPVs.

\section{Herpesviruses in Human Carcinogenesis}

\section{Are HSV 1 \& 2 Involved?}

An essential discussion is whether HSV 1 or HSV 2 might be involved in the development of can- cer in humans - this actual process could be possible through the induction of chromosomal aberra- tions or mutations of the DNA in host cells, or through an involvement of other DNA tumourviruses [zur Hausen 2011].

HSV 1 or HSV 2 could be involved in cervical, other genital, and in anal cancer. It is well known that cytological as well as histological changes induced by these viruses - mainly by HSV 2 - are often found in patients with cervical disease. Results from epidemiological as well as other studies are, however, conflicting. Infections induced by herpesviruses may play a role in the development of cervical neoplasias [zur Hausen 2011].

In a material of 233 healthy women and 333 cases of cervicitis, 210 cases of cervical intraepithel-ial neoplasia (CIN) as well as 24 cases of cervical squamous cell carcinoma (CSCC), HPV infection was found to be closely connected with CSCC and less closely to CIN. The authors conclude that HSV 2 coinfection with HPVs may be of importance in the development of cervical neoplasias [Zhao et al. 2012].

\section{Human Herpesvirus Type 8 (HHV 8)}

HHV 8 has been found to affect immune system and immune response [Crispo et al. 2001; Cirone et al. 2007; Butler et al. 2012].

\section{Essential Issue}

One important question to be solved is whether herpesviruses are involved in those $(<5 \%)$ cases of cervical cancer which are found to be HPV-negative. It is also important to realise that the percent- ages given concerning HPV-negative cases are speculative because all existing HPV types are not tested in published reports.

Further studies are indispensable to evaluate this highly essential issue of herpesviruses and car- cinogenesis.

\section{Bk Polyomavirus (BKV)}

\section{Does the BKV Coexist with HPV?}

Infections caused by the BKV usually occur in young children - most of the patients are asymptom- atic. BKV may, however, induce disease in the urinary tract, but the association between BKV and human cancer is unclear [zur Hausen 2011].

In London (UK), the BKV was isolated from the urine of an immunocompromised patient. The very same virus was later isolated from the urine of a number of patients who were immunosup-pressed the prevalence of BKV is found to be high in the general population. Humans appear to catch the BKV infection early in life but clinical disease is seldom observed [Collier et al. 2011].

The BKV is frequently detected in samples from urine especially in patients who are immunosup-pressed - both high-risk HPV and BKV can alter the control of the cell cycle as well as inhibit the apoptosis. No statistical significance was found between high-risk HPV and BKV coinfection - this interesting coexistence may, however, be a reality [Fraase et al. 2012]. 


\section{Chlamydia Trachomatis (Ct)}

\section{Is CT Involved?}

CT infection is common and sexually transmitted which often remains asymptomatic but may as a chronic disease cause e.g. inflammation in the pelvis. Several studies - epidemiological as well as seroepidemiological - indicate that CT infections may be involved in the development of cervical cancer, or in the process of CIN. CT infections may make the persistence of HPVs possible, and thus contribute to carcinogenesis in the uterine cervix [zur Hausen 2011].

\section{Human Immunodeficiency Viruses Types 1 (HIV 1) \& 2 (HIV 2)}

\section{Are HIVs Involved?}

HIV 1 and HIV 2 can be classified as indirect carcinogenes. These viruses induce immunosuppres-sion resulting in an higher incidence of tumours which are caused by other viruses - epidemiologic- al studies underline an increased incidence of anogenital intraepithelial neoplasias. Several reports confirm an increased incidence of cervical cancer in HIV-positive women. The effect of HIVs may act through two different pathways, namely either through immunosuppression or promoting the activity of HPVs [zur Hausen 2011].

\section{Discussion}

Mainly localised viral infections are those caused by HPVs, HSV 1 \& 2, adenoviruses and poxvirus [Collier et al. 2011]. In the year 2008, 12.7 million new cases of cancer were detected and $16.1 \%$ of them were caused by infections. The HPVs, hepatitis B $\& \mathrm{C}$ viruses and Helicobacter pylori counted for 1.9 million cases. In women, cervical cancer was responsible for about half of the cases pro-bably caused by infections; about $30 \%$ of the cases were detected in patients younger than 50 years of age [de Martel et al. 2012].

The high sensitivity of the polymerase chain reaction (PCR) technique allows the detection of very small amounts of DNA or
RNA of various viruses [zur Hausen 2006, 2011]. Driver genes res-ponsible for cancer are discussed by Rozenblatt-Rosen et al. [2012]. HPV is a necessary step in the cervical carcinogenesis. The pitfalls of conventional cytological screening are obvious - HPV DNA testing is now under development as an additional method to cytology [Boone et al. 2012]. HPV load was found to be an important prognostic factor in CIN $2 \& 3$ - in this study, 46 patients with CIN were compared to women without cervical disease [Bencomo-Álvarez 2012].

HPV proteins and their functions are essential in understanding why HPV infections are consider-ed a major cause of human cancer [zur Hausen 2006, 2011]. The genomic organisation as well as HPV proteins, and the oncogenic potential of different types of HPV constitute an indispensable issue [Alp Avci 2012].

Important neoplasias attributable to HPVs are cervical, vulval and vaginal cancer as well as can- cer of the penis and anus, and cancer of oropharynx [CDC 2012]. HPVs are annually estimated to count for $27.9 \%$ of the global cancer incidence linked to infections [zur Hausen 2011].

Harald zur Hausen's HPV concept is of great importance. He discusses in detail e.g. cancer of the cervix and penis, vulval and vaginal cancer as well as anal and perianal cancer, and carcinoma of the prostate gland. Cervical cancer is probably the virus-induced neoplasia which is best document-ed [zur Hausen 2011]. The association between HPV and cancer of the prostate is discussed e.g. by Dodd et al. [1993], Martinez-Fierro et al. [2010] as well as by Lin et al. [2011].

HPV self-testing is an important new method [Rubinstein 2008; Dunne et al. 2011; Gustavsson et al. 2011; LazcanoPonce et al. 2011; Jones et al. 2012; Mollers et al. 2012; Rositch et al. 2012; Snijders et al. 2012; Wolfrum et al. 2012]. In HPV testing, the DNA and RNA techniques are con-clusive [zur Hausen 2006, 2011; Johansson et al. 2007; Twiggs \& Hopkins 2011; Chan et al. 2012; Guan et al. 2012]. 
HPV detection from urine is an interesting aspect - this technique is discussed by Vorsters et al. [2011] and by Tanzi et al. [2012] as well as by Thilagavathi et al.[2012].

HPV vaccination programmes are going on - we have to see whether these programmes prevent invasive cancers. It is interesting to find that only $18 \%$ out of 205 staff nurses in the Rural Institute of Medical Sciences and Research, Saifai, Etawah in India knew about HPV vaccination [Singh et al. 2012]. Totally, 360 consecutive outpatients of a dermatological clinic were interviewed about HPV infections, genital and anal warts as well as cancer using a self-administred questionnaire - 77.2\% answered the quostions; $39.4 \%$ of the outpatients had heard about HPV-induced infections and 23.9\% about HPV vaccination [Kuznetsov et al. 2012].

Cancer of the head and neck including oral cancer is discussed by zur Hausen [2011], Joseph \& D'Souza [2012], Minn [2012], Edelstein et al. [2012], Lee et al. [2012] and Paolini et al. [2012]. Oropharyngeal cancer is an important neoplasm to study due to oral sex which exposes individuals to HPVs [Minn 2012]; also zur Hausen [2011] underlines the importance of oral sex in the devel-opment of oropharyngeal cancer.

Ocular surface squamous neoplasia, that is conjunctival squamous neoplasia, is a highly intersting tumour which is evaluated by Scott et al. [2002], Biswas et al. [2010], Aktas et al. [2012], Chauhan et al. [2012], Di Girolamo [2012] as well as by Kao et al. [2012].

The possible involvement of HSV 1 and HSV 2 in human carcinogenesis is essential to evaluate -HSV 1 or HSV 2 , or both of them could be involved in genital and anal cancer. Cellular and histo-pathological HSV-induced changes are apparently often found in cervical disease. For the time being, the obtained results concerning cervical cancer and other genital neoplasias as well as anal cancer are conflicting [zur Hausen 2011].
HHV 8 has been demonstrated to have effect on immune system as well as on immune response [Crispo et al. 2001; Cirone et al. 2007; Butler et al. 2012]. The important question whether herpesviruses are involved in the carcinogenesis of the uterine cervix as well as of some other organs will be discussed in a separate paper.

The possible coexistence between high-risk HPV and BKV is interesting [Fraase et al. 2012]. In-volvement of CT and HIV 1 \& HIV 2 in cervical carcinogenesis is possible [zur Hausen 2011].

\section{Summary}

Cervical, vulval, vaginal, penile, anal, orophraryngeal as well as conjunctival cancers are important human papillomavirus (HPV)-induced neoplasias HPVs count annually worldwide for about $28 \%$ of the cancer incidence attributable to infections. Harald zur Hausen's HPV concept is highly indis-pensable.

HPV self-testing is an essential new method of HPV detection and is now gaining increasing im- portance as an act of early diagnosis of persistent HPV infections. The method of self-testing is fre- quently discussed in the literature. Another important move is HPV vaccination - until further no- tice, we are, however, not able to evaluate the true effect of the HPV vaccination programmes.

The importance of HPV infections in carcinogenesis is well documented herpesviruses types 1,2 and 8 are interesting in this respect.

We declare that we have no conflicts of interest.

\section{References}

Aktas, N., Ersoy, A., Yazici, B., Kilic, N. \& Aytac, B. (2012). "Isolated Ocular Surface Squamous Neoplasia in Renal Transplant Recipient," Expr Clin Tranplant 2012;10:506-7. 
Alp, A. G. (2012). "Genomic Organization and Proteins of Human Papillomavirus," Mikrobiyol Bul 2012;46:507-15.

Appelby, P., Beral, V., Barrington de González, A. et al. (2007). "Cervical Cancer and Hormonal Contraceptives: Collaborative Rean-Alysis of Indiviudual Data for 16,573 Women with Cervical Cancer and 35,509 Women without Cervical Cancer from 24 Epidemiological Studies," Lancet 2007;370:1609-21.

Bencomo-Álvarez, A. E., Limones-Perches, I., Suárez-Rincón, A. E., Ramírez-Jirano, L. J., Borrayo-Carbajal, E., Sánchez-Corona, J. \& Montoya-Fuentes, H. (2012). "Human Papillomavirus Viral Load in Cervical IntraEpithelial Neoplasia as a Prognostic Factor in a Mexican Population," Genet Mol Res 2012;11(AOP).

Biswas, J., Krihnakumar, S. \& Ahuja, S. (2010). Manual of Ocular Pathology, New Delhi. Jaypee Brothers Medical Publishers (P) Ltd, 2010.

Boone, J. D., Erickson, B. K. \& Huh, W. K. (2012). "New Insights into Cervical Cancer Screening," J Gynecol Oncol 2012;23:282-7.

Butler, L. M., Jeffery, H. C., Wheat, R. L., Long, H. M., Rae, P. C., Nash, G. B. \& Blackbourn, D. J. (2012). "Kaposi's Sarcoma-Associated Herpesvirus Inhibits Expression and Function of Endothelial Cell Major Histocompatibility Complex Clas II Suppressor of Cytokinesignaling 3," J Virol 2012;86:7158-66.

Cann, A. J. (2005). "Principles of Molecular Virology," 4th edition. Amsterdam. Elsevier Academic Press, 2005.

Chan, P. K. S., Picconi, M. A., Cheung, T. H., Giovannelli, L. \& Park, J. S. (2012). "Laboratory and Clinical Aspects of Human papillomavirus Testing," Crit Rev Clin Lab Sci 2012;49:117-36.

Chauhan, S., Sen, S., Sharma, A., Dar, L., Kashyap, S., Kumar, P., Bajaj, M. S. \& Tandon, R. (2012). "Human Papillomavirus: A Predictor of Better Survival in Ocular
Surface Squamous Neoplasia Patients," Br J Ophthalmol 2012; ahead of print.

Cirone, M., Lucaria, G., Bergamo, P., Trivedi, P., Frati, L. \& Faggioni, A. (2007). "Human Herpesvirus 8 (HHV-8) Inhibits Monocyte Differentiation into Dendritic Cells and Impairs Their Immunostimulatory Activity," Immunol Lett 2007;113:40-6.

Collier, L., Kellam, P. \& Oxford, J. (2011). Human Virology, 4th edition. Oxford. Oxford University Press, 2011.

Crispo, A., Tamburini, M., De Marco, M. R. et al. (2011). 'HHV-8 Prevalence, Immunosuppression and Kaposi's Sarcoma in South Italy,' Int J Mol Med 2011;7:535-8.

Danaei, G. (2012). "Global Burden of Infection-Related Cancer Revisited," Lancet Oncol 2012;13:564-5.

de Martel, C., Ferlay, J., Francheschi, S., Vignat, J., Bray, F., Forman, D. \& Plummer, M. (2012). "Global Burden of Cancers Attributable to Infections in 2008: A Review and Synthetic Analysis," Lancet Oncol 2012;13:607-15.

Di Girolamo, N. (2012). "Association of Human Papilloma Virus with Pterygia and Ocular-Surface Squamous Neoplasia," Eye 2012;26:201-11.

Dodd, J. G., Paraskevas, M. \& McNicol, P. J. (1993). "Detection of Human Papillomavirus 16 Transcriptions in Human Prostate Tissue," J Urol 1993;149:400-2.

Dunne, E. F., Sternberg, M., Markowitz, L. E., McQuillan, G., Swan, D., Patel, S. \& Unger, E. R. (2011). "Human Papillomavirus (HPV) 6, 11,16 , and 18 Prevalence in the United States - National Health and Nutrition Examination Survey, 2003-2006: Opportunity to Measure HPV Vaccine Impact?," J Infect Dis 2011;204:562-5.

Edelstein, Z. R., Schwartz, S. M., Hawes, S. et al. (2012). "Rates and Determinants of Oral Human Papillomavirus Infection in Young Men," Sex Transm Dis 2012;39:860-7. 
Ferlay, J., Bray, F., Pisani, P. et al. (editors). (2004). 'The Global Age-Standardized Rate of Cancer of the Cervix,' Globogan 2002. Cancer Incidence, Mortality and Prevalence Worldwide. IARC Cancer Base No. 5. Lyon. IARCPress, 2004.

Ferlay, J., Forman, D., Mathers, C. D. et al. (2012). "Breast and Cervical Cancer in 187 Countries between 1980 and 2010," Lancet 2012;379:1390-1.

Forouzanfar, M. H., Foreman, K. J., Delossantos, A. M. et al. (2011). "Breast and Cervical Cancer in 187 Countries between 1980 and 2010: A Systematic Analysis," Lancet 2011;378:1461-84.

Fraase, K., Hart, J., Wu, H. et al. (2012). "BK Virus as a Potential Co-Factor for HPV in the Development of Cervical Cancer," Ann Clin Lab Sci 2012;42:130-4.

Guan, P., Howell-Jones, R., Lin, N. et al. (2012). "Human Papillomavirus Types in 115,789 HPV-Positive Women: A MetaAnalysis from Cervical Infection to Cancer," Int J Cancer 2012.

Gustavsson, I., Sanner, K., Lindell, M. et al. (2011). "Type-Specific Detection of HighRisk Human Papillomavirus (HPV) in SelfSampled Cervicovaginal Cells Applied to FTA Elute Cartridge," $\mathrm{Br} J$ Cancer 2011;51:255-8.

Johansson, B. C., Andersson, S. \& Hjerpe, A. (2007). "Väl Underbyggd Roll för Analys av HPV Vid Cervixcancerprevention," Läkartid- ningen 2007,104:608.

Jones, H. E., Brudney, K., Sawo, D. J. et al. (2012). "The Acceptability of a selfLavaging Device Compared to Pelvic Examination for Cervical Cancer Screening among Low-Income Women," J Womens Health 2012; ahead of print.

Joseph, A. W. \& D’Souza, G. (2012). "Epidemiology of Human PapillomavirusRelated Head and Neck Cancer," Otolaryngol Clin North Am 2012;45:379-64.

Kao, A. A., Galor, A., Karp, C. L. et al. (2012). "Clinicopathologic Correlation of Ocular Surface Squamous Neoplasms at Bascom
Palmer Eye Institute: 2001 to 2010," Ophthalmology 2012;119:1773-6.

Kuznetsov, L., Reitmaier-Weber, C. M., Ruzicka, T. et al. (2012). "Awareness of Human Papillomavirus Infection, Genitoanal Warts and Cancer in a Dermatological Outpatient Clinic Setting," Acta Derm Venerolog 2012.

Lazcano-Ponce, E., Lorincz, A. T., CruzValdez et al. (2011). "Self-Collection of Vaginal Specimens for Human Papillomavirus Test-Ing in Cervical Cancer Prevention (MARCH): A Community-Based Randomised Controlled Trial," Lancet 2011;378:1868-73.

Lee, L. A., Huang, C. G., Liao, C. T. et al. (2012). "Human Papillomavirus-16 Infection in Advanced Oral Cavity Cancer Patients is Re-Lated to a Increased Risk Of Distant Metastases and Poor Survival," PloS One 2012;7:e40767.

Lin, Y., Mao, Q., Zheng, X. et al. (2011). "Human Papillomavirus 16 or 18 Infection and Prostate Cancer: A Meta-Analysis," Ir J Med Sci 2011;180:497-503.

Martinez-Fierro, M. I., Lech, R. J., ComezGuerra, L. S. et al. (2010). "Identification of Viral Infections in the Prostate and Evaluation of Their Association with Cancer," BMC Cancer 2010;10:326.

Minn, H. (2012). 'Pään Ja Kaulan Alueen Syöpä - Uhkaako Papillomaviruksen Aiheuttama Epidemia?,' Erikoislääkäri 3/2012:141-3.

Mollers, M., Scherpenisse, M., van der Klis, F. R. et al. (2012). "Prevalence of Genital HPV Infections and HPV Serology in Adoles-Cent Girls, Prior to Vaccination," Cancer Epidemiol 2012; ahead of print.

Paolini, F., Rizzo, C., Sperduti, I. et al. (2012). "Both Mucosal and Cutaneous Papillomaviruses are in the Oral Cavity but Only Alpha Genus Seems to be Associated with Cancer," J Clin Virol 2012;pii: S13866532(12)00378-2.

Rositch, A. F., Gatuguta, A., Choi, R. Y. et al. (2012). "Knowledge and Accetability of Pap 
Smears, Self-Sampling and HPV Vaccination among Adult Women in Kenya," PLoS One 2012;7:e40766.

Rozenblatt-Rosen, O., Deo, R. C., Padi, M. et al. (2012). "Interpreting Cancer Genomes Using Systematic Host Network Perturbations by Tumour Virus Proteins," Nature 2012;487:491-5.

Rubinstein E. Kvinnor (2008). "Positiva till Självutförda HPV-Test," Läkartidningen 2008;105:467-8.

Scott, I. U., Karp, C. L. \& Nuovo, G. J. (2002). "Human Papillomavirus 16 and 18 Expression in Conjunctival Intraepithelial Neoplasia," Ophthalmology 2002;109:54247.

Singh, E., Seth, S., Rani, V. et al. (2012). "Awareness of Cervical Cancer Screening among Nursing Staff in a Tertiary Institution of Rural India," J Gynecol Oncol 2012;23:141-6.

Snijders, P. J., Verhoef, V. M. J., Arbyn, M. et al. (2012). "High-Risk HPV Testing on SelfSampled Versus Clinician-Collected Specimens: A Review on the Clinical Accurracy and Impact on Population Attendance in Cervical Cancer Screening," Int J Cancer 2012.

Tanzi, E., Bianchi, S., Fasolo, M. M. et al. (2012). "High Performance of a New PCRBased Urine Assay for HPV-DNA Detection and Genotyping," J Med Virol 2012.

The Centers of Disease Control and Prevention (CDC). (2012). "Morbidity and Mortality Weekly Report," JAMA 2012;308:445-7.

Thilagavathi, A., Shanmughapriva, S., Vinodhini, K. et al. (2012). "Prevalence of Human Papillomavirus (HPV) among College Going Girls Using Self Collected Urine Samples from Tiruchirappalli, Tamilnadu," Arch Gynecol Obstet 2012; ahead of print.

Twiggs, L. B. \& Hopkins, M. (2011). "HighRisk HPV DNA Testing and HPV-16/18 Genotyping: What is the Clinical
Application?," J Low Genit Tract Dis 2011;15:224-30.

Vorsters, A., Micalessi, I., Bücke, J. et al. (2011). "Detection of Human Papillomavirus DNA in Urine. A Review of the Literature," Eur J Clin Microbiol Infect Dis 2011.

Wolfrum, S. G., Koutsky, L. A., Hughes, J. P. et al. (2012). "Evaluation of Dry and Wet Transport of at-Home Self-Collected Vaginal Swabs for Human Papillomavirus Testing," J Med Microbiol 2012; ahead of print.

Zhao, Y., Cao, X., Zheng, Y. et al. (2012). "Relationship between Cervical Disease and Infection with Human Papillomavirus Types 16 and 18, and Herpes Simplex Virus 1 and 2," J Med Virol 2012;84:1920-7.

zur Hausen, H. (2006). "Infections Causing Human Cancer," Weinheim. Verlag WILEYVCH, 2006.

zur Hausen, H. (2011). "Infections Causing Human Cancer," Weinheim. Wiley Blackwell, 2011. 